\title{
3D Simulation of Deflection Basin of Pavements under High-Speed Moving Loads $^{1}$
}

\author{
Yong Deng \\ Zachry Department of Civil Engineering \\ Texas A\&M University \\ 3135 TAMU, CE/TTI Bldg. 508K \\ College Station, Texas, 77843 \\ Phone: (979) 213-2625 \\ Email: dengyong1992@tamu.edu \\ Xue Luo, Ph.D. \\ College of Civil Engineering and Architecture \\ Zhejiang University \\ 866 Yuhangtang Road, An-zhong Bldg. B813 \\ Hangzhou 310058, China \\ Office: +86 571-88206542 \\ Email:xueluo@zju.edu.cn \\ Fan Gu, Ph.D. \\ National Center for Asphalt Technology \\ Auburn University \\ 277 Technology Parkway, Auburn, AL 36830 \\ Phone: (334) 844-6251 \\ Email: fzg0014@auburn.edu \\ Yuqing Zhang, Ph.D. \\ Lecturer in Highway Engineering \\ School of Engineering and Applied Science \\ Aston University \\ Aston Triangle, Birmingham, B4 7ET, U.K. \\ Phone: +44 (0) 121-204-3391 \\ Email: y.zhang10@aston.ac.uk \\ Robert L. Lytton, Ph.D., P.E. \\ Zachry Department of Civil Engineering \\ Texas A\&M University \\ 3136 TAMU, CEOB 503A, College Station, Texas 77843 \\ Phone: (979) 845-9964 \\ Email: r-lytton@civil.tamu.edu
}

\footnotetext{
${ }^{1}$ This is an Accepted Manuscript of an article published by Construction and Building Materials. Access to the full
} text of the paper is available at https://doi.org/10.1016/j.conbuildmat.2019.07.228 


\begin{abstract}
The nondestructive testing of pavements currently has become more focused on continuous deflection profiles and vehicle moving speeds, which are recognized to be critical in obtaining complete and accurate pavement responses and conditions. However, current techniques cannot produce satisfactory results in terms of continuous deflection profiles at high-speed moving loads. Under this circumstance, the computational simulation is a good alternative. The objective of this study is to utilize the three-dimensional (3D) finite element (FE) analysis to investigate the characteristics of deflection basins of pavements under high-speed moving loads. Specifically, a 3D FE pavement model is constructed with six sets of pavement materials representing six types of pavements and four moving speeds $(24 \mathrm{~km} / \mathrm{h}, 40 \mathrm{~km} / \mathrm{h}, 64 \mathrm{~km} / \mathrm{h}$, and $80 \mathrm{~km} / \mathrm{h})$. The results demonstrate that the deflection basin of a pavement exhibits an asymmetric shape under a highspeed moving load. It also reveals that there is a time lag between the maximum deflection and the center of the load in flexible pavements. This time lag is utilized to define a new term of "lag angle". The effects of the material viscoelasticity, structural inertia damping, moving speed, and pavement deterioration conditions on the shape and lag angle of the deflection basin are illustrated. Furthermore, it is found that the lag angle of the deflection basin is closely related to the phase angle of the viscoelastic pavement materials. Finally, the deflection basins predicted by the 3D FE analysis are proven to be comparable to the field deflections obtained at a high moving speed.
\end{abstract}

Keywords: 3D finite element modelling; moving load; deflection basin; phase angle; lag angle; deterioration condition 


\section{Introduction}

The evaluation and prediction of pavement conditions during and after construction are longterm and essential processes for rehabilitations, corrections and future designs of pavements. The methodology of nondestructive testing (NDT) is generally used to reflect in-situ responses and material properties of pavements without causing any destruction to the pavement. Two major types of measurements are used for pavement evaluation: deflections and dynamic material properties. The first type is the most straightforward structural response of pavements under loads. Testing devices currently in use can collect deflection information including continuous deflected profiles, maximal or mean values of deflections over testing sections. The other type of measurement includes modulus of surfaces and supporting layers. Typically, such values are obtained from complete deflection-time histories of a pavement under dynamic loads using backcalculation procedures. Based on the types of measurements obtained from NDT devices, the existing nondestructive testing can be divided into the deflection-based approach and seismic-based approach (1). Typical nondestructive testing devices include Falling Weight Deflectometer (FWD), Rolling Wheel Deflectometer (RWD) and Traffic Speed Deflectometer (TSD).

The FWD is currently one of the most widely used nondestructive testing devices. It generates haversine-shaped dynamic loads and measures the time history of deflections by the sensors mounted along the centerline of the load plate. The peak value of the deflection data can be used for backcalculation of the subgrade resilient modulus and the effective structural number SN (2). Besides, more complicated material properties such as moduli, damping, and fracture and permanent deformation can be obtained from deflection basins (3). The RWD is a deflection-based device. It records deflections of the pavement surface at a highway speed (up to $105 \mathrm{~km} / \mathrm{h}$, i.e. $65 \mathrm{mph}$ ). The deflection that is used for evaluation is typically the averaged value from a sample unit length since the averaged deflection is less vulnerable to random errors associated with all individual deflections (4). The TSD is another device which moves at a highway speed (up to $96 \mathrm{~km} / \mathrm{h}$ ) during the test. It applies Doppler lasers to measure the vertical surface deflection velocity, which is used to generate the deflection basin of the pavement surface (5).

Comparing these three nondestructive testing devices, each has its strengths and weakness. For the RWD and TSD testing, the highway speed of the testing vehicle ideally 
represents traffic conditions of in-service pavements and remarkably enhances the productivity of testing. Besides, continuous deflection profiles provide complete features of pavements which include special spots and structures such as soft spots, cracks and section joints. However, the speed affects the accuracy of collected data and increases the difficulty in data acquisition (4).

For the FWD, it is generally acknowledged that data from the FWD are more reliable and deflections obtained from the RWD are often compared with the FWD results to prove viability, repeatability and sensitivity (4). Besides, material properties of pavement layers such as dynamic moduli backcalculated from deflection basins obtained by the FWD are commonly used to evaluate conditions of flexible pavements. However, there remain limitations about the application of the FWD as an evaluation tool for pavements. First, its low production not only limits its use for timely and comprehensive evaluation of the whole pavement, but also significantly increases costs and safety problems due to the traffic control and interruption. Secondly, the device only considers dynamic properties of tire loads, but ignores the effects of moving vehicles on pavement responses (6).

A brief review of the common NDT devices above reveals the advantages of continuous deflection profile and importance of vehicle moving speeds in obtaining complete and accurate pavement responses. However, the operation of the highway-speed NDT device, like the TSD, is usually expensive and limited. To justify its use on pavement networks, it must provide comprehensive pavement network asset information which can be used to make cost-effective maintenance and rehabilitation decisions. This requires the ability to analyze the measured results objectively and, if possible, provide timely advanced warning of impending costly levels of future distress. This objective analysis can be achieved through the use of the numerical computations to simulate pavement responses in real conditions. The purpose of the numerical simulation is to provide a sound and consistent mechanics-based method of interpreting the results. The Finite Element (FE) models have been widely used due to its low expenses, high efficiency and desirable matches with in-service pavements. Many techniques have been developed and incorporated in the finite element codes and softwares for simulation of loading, geometry and material characterization (7). The simulated responses of pavements are then compared with field data from NDT devices or instrumented pavement sections to evaluate the accuracy of FE models. A few examples are reviewed herein. 
Zaghloul and White (8) built a three-dimensional (3D) elastic multilayer system in the FE software ABAQUS to simulate uncracked pavements under moving loads. The moving load was represented by a step function of which the duration is controlled by the moving speed.

Numerical results were compared with discrete field measurements including horizontal strains and surface deflections. The numerical results showed good matches with the field data. Uddin et al. (9) built a three-layer elastic system to simulate both uncracked and cracked pavements under static and dynamic loads. The moduli of the layers were obtained from the FWD backcalculation; the dynamic load of the FWD was simulated using a uniform pressure of which the magnitude varies with time.

Mulungye et al. (10) built a 2D model in the software ANSYS using a viscoelastic surface layer to predict responses of flexible pavements under single and multiple axle loads. The moving loads were simulated as cyclic loads distributed uniformly on the pavement. A good agreement between predicted and measured strains at the bottom of the surface layer showed the applicability of FE models in flexible pavements. Li et al. (11) applied an improved 2D axisymmetric model for flexible pavements with a stress-dependent supporting layer. Effects of viscoelasticity and nonlinearity of materials on pavement responses under dynamic FWD loads were discussed.

Based on the studies on tire-pavement contact stresses (12, 13), Al-Qadi et al. (14) and Li et al. (15) applied continuously moving loads distributed nonuniformly on flexible pavements in the FE models. Predicted responses of pavements such as tensile strains at the bottom of the surface and stresses in the base layer were compared with the measured data. Results showed the loading configuration has significant effects on pavement responses.

The studies described above highlight the development of FE models in terms of material properties and loading configurations of pavements. There are few studies that focus on generating continuous deflection profiles with highway speeds. Thus, it is the goal of this study to investigate the characteristics of continuous deflection profiles of a pavement under highspeed moving loads. Furthermore, the characteristics of continuous deflection profiles to different materials, structures and moving speeds will be investigated. The $3 \mathrm{D}$ computational simulation is an effective technique for this purpose with the combination of different pavement types, conditions, and moving speeds. The technical background regarding the viscoelastic pavement responses under a moving load is first introduced in the next section. Then the 
construction of a 3D pavement model with a moving load is presented. The simulation results for different pavement types, conditions, and moving speeds are subsequently presented and discussed. Furthermore, a case study is given to validate the simulated pavement deflections using the measured continuous deflections by the RWD and TSD in the field. The final section summarized the major findings of this work.

\section{Viscoelastic Deflection Basin under a High-speed Moving Load}

In order to study the characteristics of continuous deflection profiles of a pavement under traffic loading, the traffic loads and pavement responses need to be accurately represented. It means that two critical characteristics of traffic loading - moving speeds and fundamental dynamic properties of vehicles (period of vibration, etc.) should be considered. These two characteristics can be modeled as combinations of springs and dampers such as the quarter-car suspension model (16). In the analytical and computational applications of layered pavement systems, the traffic loads are usually simplified as haversine-shaped dynamic loads (17). The impact of traffic speeds on flexible pavements is examined by adjusting the period of the haversine function (18). It is concluded that the structural inertial damping causes a lag distance between the maximum deflection and the traffic load. It also demonstrates that higher moving speeds decreases magnitudes of strains for all pavement layers while making the response peak lag further behind the load (18). The pavement responses are usually regarded as the response model to a dynamic load, which include both the stiffness and inertial damping of the structure. However, some existing pavement response models use an elastic modulus and ignore the effect of inertial damping of the structure $(3,18)$. Also, for flexible pavements the viscoelasticity of pavement materials is an important factor affecting the responses of the pavement. In a recent study (19), the inertia and viscoelastic properties of the surface and supporting layers are taken into consideration for some rigid and flexible pavements. The analytical model was evaluated using measured data from the FWD. The good match shows that both viscoelasticity and inertia of pavement materials have effects on responses of pavements to dynamic loads applied by the FWD.

Considering both the inertial damping of the structure and viscoelasticity of pavement materials, this study proposes a hypothesis for the pavement responses under high-speed moving loads: an asymmetric deflection basin with a steep leading edge and a shallow trailing edge as 
shown in Figure 1. There is a lag angle between the traffic load and the maximum deflection point in the basin. The location where the maximum deflection occurs falls behind the contact point of the tire and the pavement surface.

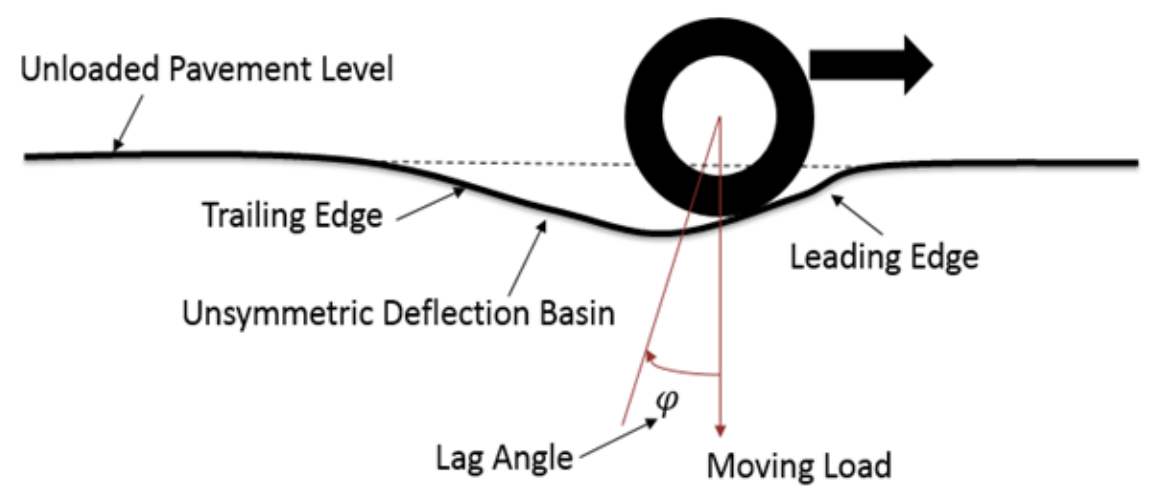

Figure 1. Illustration of Deflection Basin of a Pavement under a High-speed Moving Load

The phenomenon of the lag between the load and response is observed in the dynamic modulus test on viscoelastic materials, in which oscillatory loads are applied. The time lag between peaks of the stress and strain is used to obtain the phase angle and dynamic modulus which represent viscoelasticity of materials (20). The phase angle between the stress and strain is defined as:

$$
\delta=2 \pi \Delta t / T
$$

where $\delta=$ phase angle between the stress and strain of the material; $\Delta t=$ time lag between peaks of the stress and strain within one cycle; $T=$ period of an oscillatory load.

Similarly, the lag phase between the traffic load and maximum deflection is defined as follows:

$$
\varphi=2 \pi \Delta t^{\prime} / T^{\prime}
$$

in which

$$
T^{\prime}=L / v
$$

where $\varphi=$ lag angle between the traffic load and maximum deflection; $\Delta t^{\prime}=$ time lag between the center line of the traffic load and maximum deflection within one deflection basin; $T^{\prime}=$ period of a deflection basin; $L=$ length of the deflection basin; $v=$ speed of the traffic load.

It is widely known that the dynamic modulus and phase angle represent the current damaged condition of a pavement material, especially pointing out the specific state during its whole service life. Fatigue tests have been conducted to study how material properties vary with 
load cycles $(21,22,23)$, as shown in Figure 2. Based on previous tests conducted on asphalt mixtures, the curve of modulus versus loading cycles shows four characteristic regions (23). In the region of crack formation, the value of the modulus goes through a rapid decrease. Reese (22) has found that at the starting point of this region, the phase angle of the mixture reaches its maximum value, then it begins to drop quickly. Such a pattern shows that the phase angle is a good indicator of fatigue failure of the material.

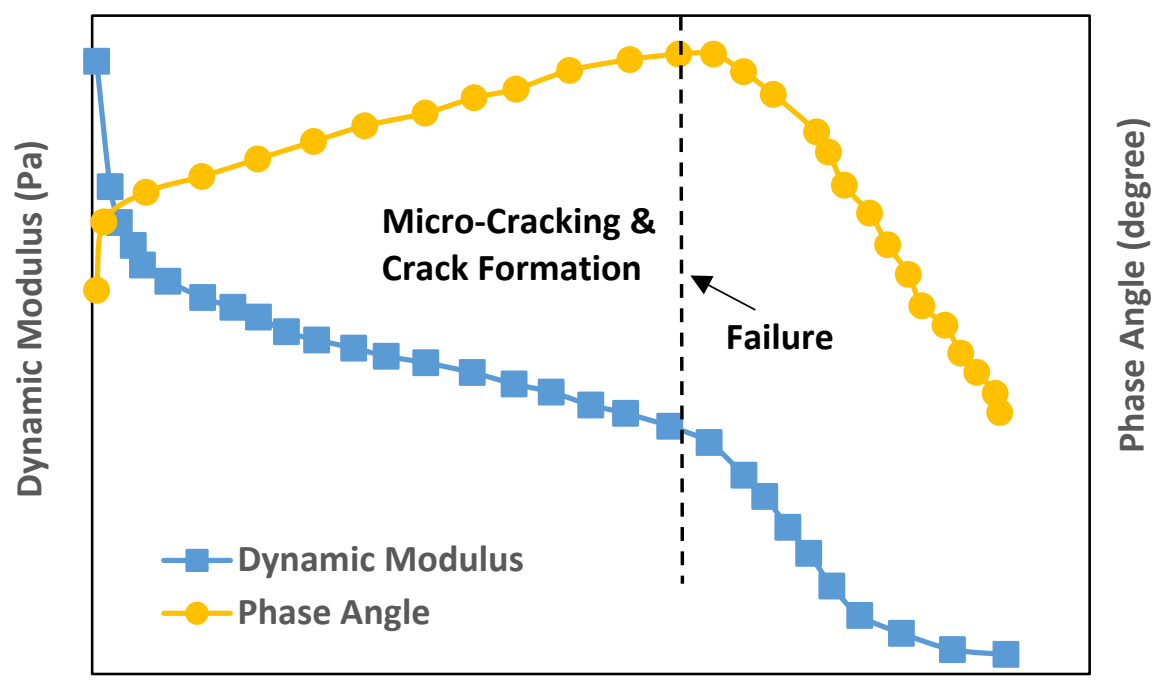

Number of Load Cycles

Figure 2. Change of Dynamic Modulus and Phase Angle of Asphalt Mixtures with the Increase of Load Cycles

As shown in Figure 2, the change of the dynamic modulus and phase angle reflects different stages of deterioration of the pavement material. A potential application of such features is the advance warning of pavement deterioration, which is necessary for optimal plans of preventive maintenance and rehabilitation. In the current state of practice, the deflection (e.g. from the FWD) is usually taken as an indicator of pavement conditions. However, the change of the deflection value is not only attributed to the loss of structural strength due to damage, but also the geometric discontinuity of the pavement. For instance, a large value of the deflection could be caused by the occurrence of cracking and rutting, or the existence of slab joints or softening due to moisture infiltration. As a result, a measurement that is directly and solely related to pavement deterioration conditions should be adopted for the purpose of advance warning. Given the similarity between the phase angle in Equation 1 and the lag angle in 
Equation 2, the lag angle is proposed herein as such a measurement. It is obtained easily from a moving deflection basin, and, as a hypothesis, it has a close relationship with the phase angle of the material, which is indicative of pavement conditions in terms of the initiation and growth of cracks.

In sum, this study proposes two hypotheses, which will be examined in the following sections using the 3D finite element (FE) modeling:

- The deflection basin of a pavement exhibits an asymmetric shape under a high-speed moving load. The shape of the deflection basin changes for different pavement types, conditions and moving speeds;

- The lag distance between the traffic load and maximum deflection and lag angle in a deflection basin have close relationships with the pavement type, moving speeds and the phase angles of the pavement materials. It is indicative of pavement deterioration conditions.

In order to prove these two hypotheses, the next section describes the procedure to construct the 3D pavement model as well as the cases to be performed in the numerical simulations.

\section{3D FE Simulation of Deflection Basins under Moving Loads}

\subsection{D pavement structure and moving load models}

To simulate real conditions of a pavement, a 3D pavement structure is built using the software ABAQUS. It consists of two pavement structures: (1) a $0.152 \mathrm{~m}$ (6-in) surface layer, a $0.304 \mathrm{~m}$ (12-in) base course, and a $1.778 \mathrm{~m}$ (70-in) subgrade; and (2) a $0.152 \mathrm{~m}$ (6-in) surface layer, a $0.152 \mathrm{~m}$ (6-in) treated base, a $0.152 \mathrm{~m}$ (6-in) unbound base, and a $1.778 \mathrm{~m}$ (70-in) subgrade. The former pavement structure is shown in Figure 3 as an example. The adjacent layers are considered as fully bonded with each other. The entire model is meshed using hexahedron elements, as shown in Figure 4. The mesh size in the vertical direction is based on the thickness

of each layer. In the lateral and horizontal directions, finer meshing is applied in the two loading paths, representing loads applied by dual tires. 


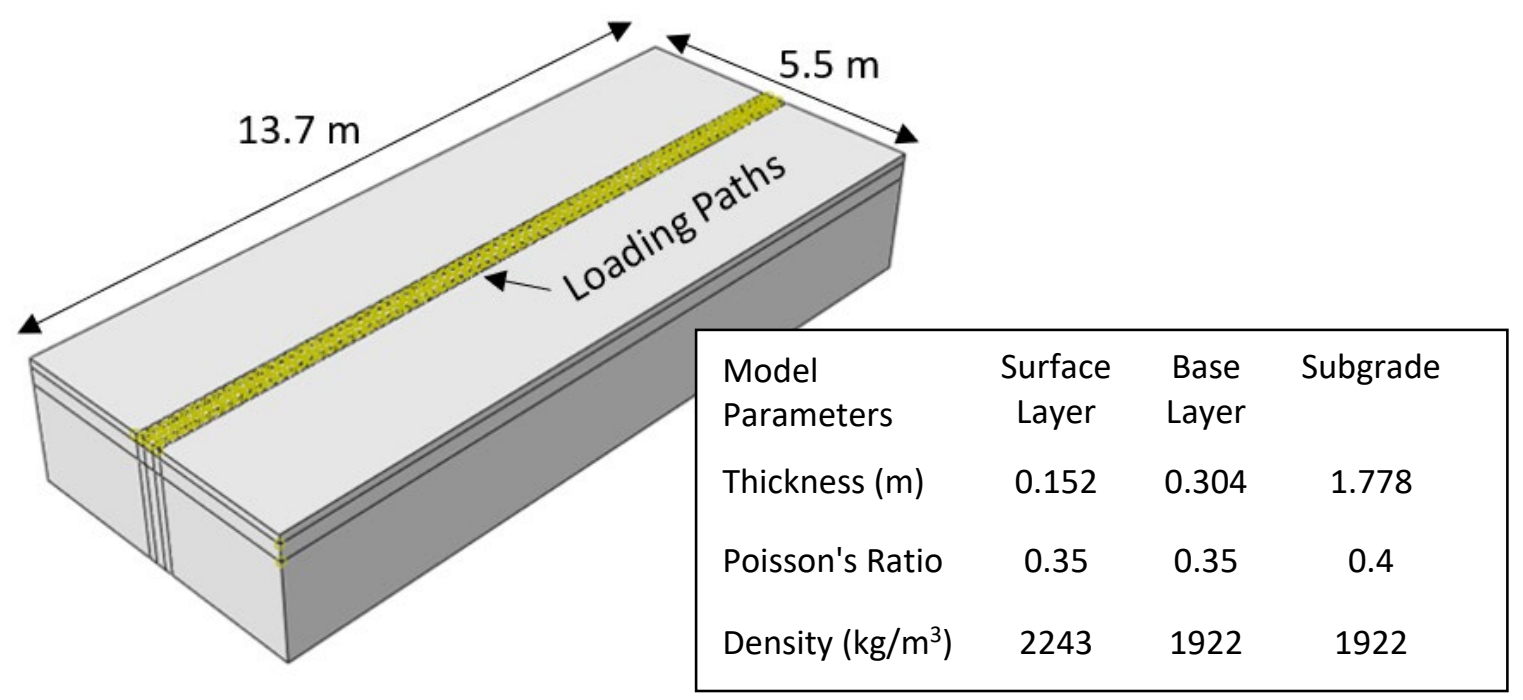

Figure 3. The 3D Pavement Structure and Parameters Used in the FE Analysis

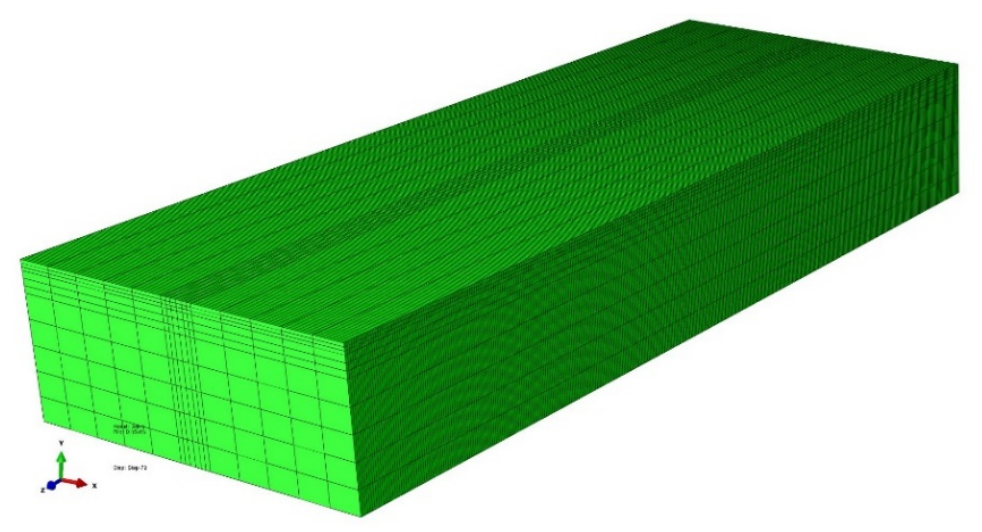

(a) Entire Pavement Structure

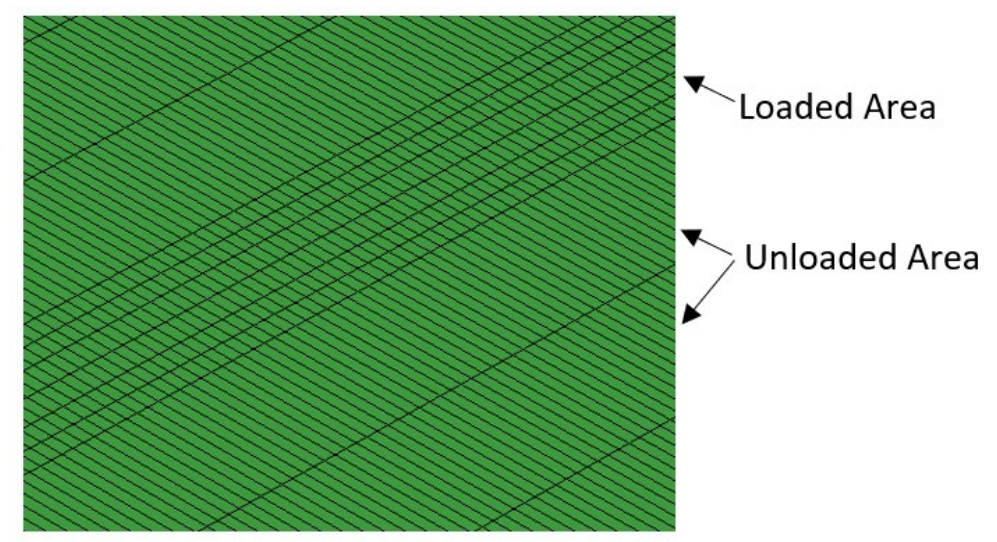

(b) Pavement Surface

Figure 4. The Meshed Models in the FE Analysis 
A 315/80R22.5 dual-tire vehicle is selected as a typical traffic loading (24). The contact load is $40 \mathrm{kN}$ and tire inflation pressure is $689.5 \mathrm{kPa}$. The tire-pavement interactions are represented based on a comprehensive study by De Beer et al. (12), which characterized typical contact stress distributions based on the simultaneous measurements of moving tires and pavement interface contact stresses. When tires act on the surface of the pavement, the contact stress between each tire and the pavement surface is composed of stresses in vertical, longitudinal and transverse directions. The magnitude and distribution of the contact stress rely on the tire type, tire inflation pressure and constant load on the tire. Figure 5 shows the distributions of the contact stresses of the selected vehicle load in three directions on the pavement surface. The magnitudes of the vertical, longitudinal and transverse stresses are 1350.7 $\mathrm{kPa}, 193.7 \mathrm{kPa}$ and $247 \mathrm{kPa}$ respectively. The values of vertical and longitudinal contact stresses change along the direction of tire length and keep constant in the direction of tire width, while the value of transverse contact stress changes along both directions.

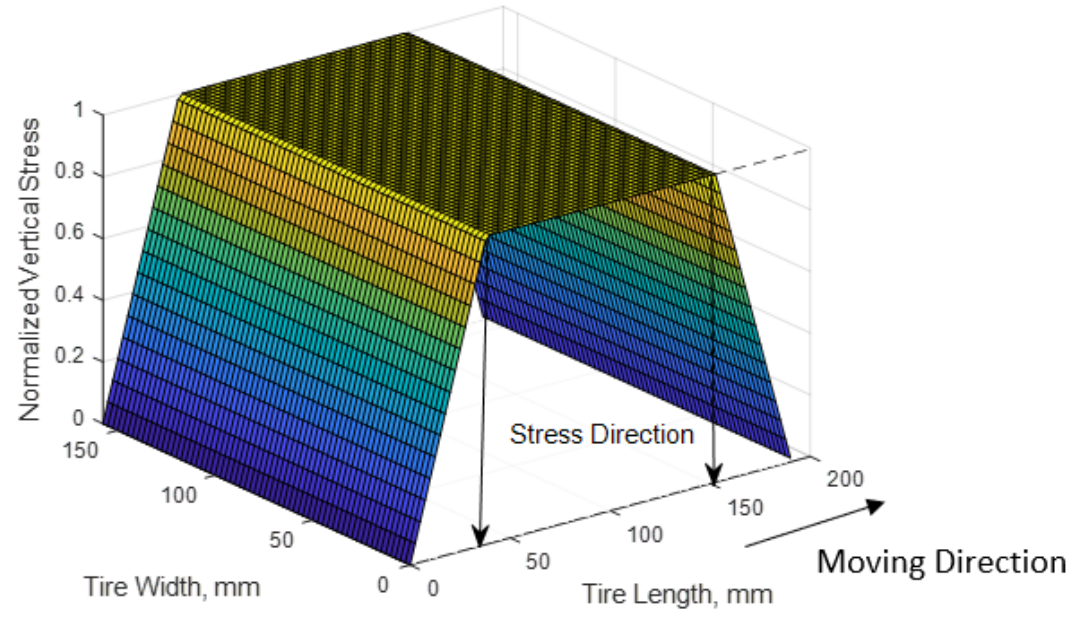

(a) Vertical Contact Stress 


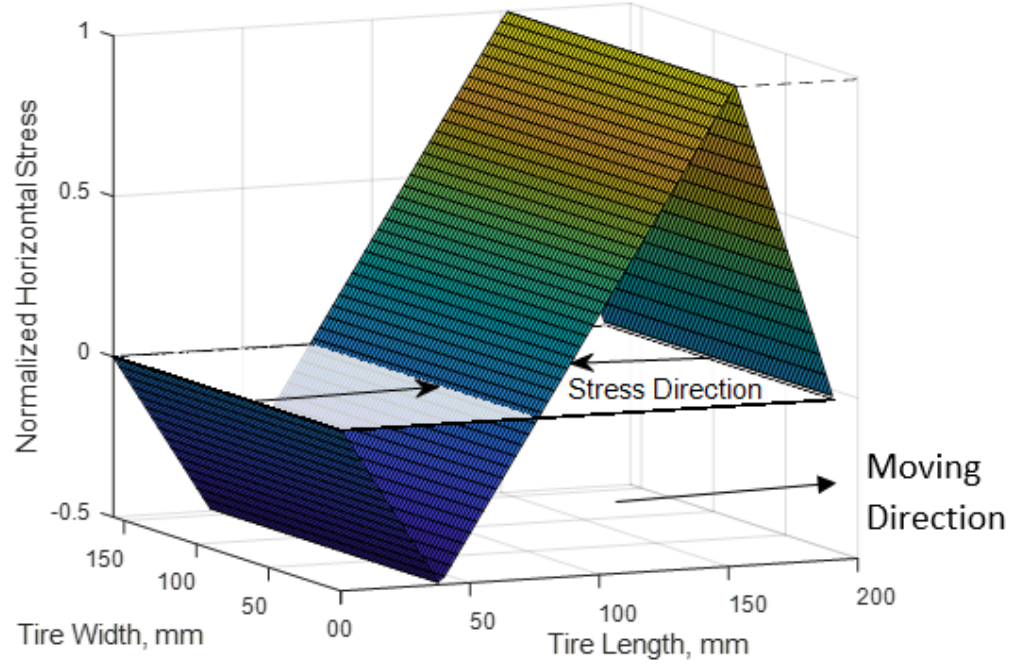

(b) Longitudinal Contact Stress

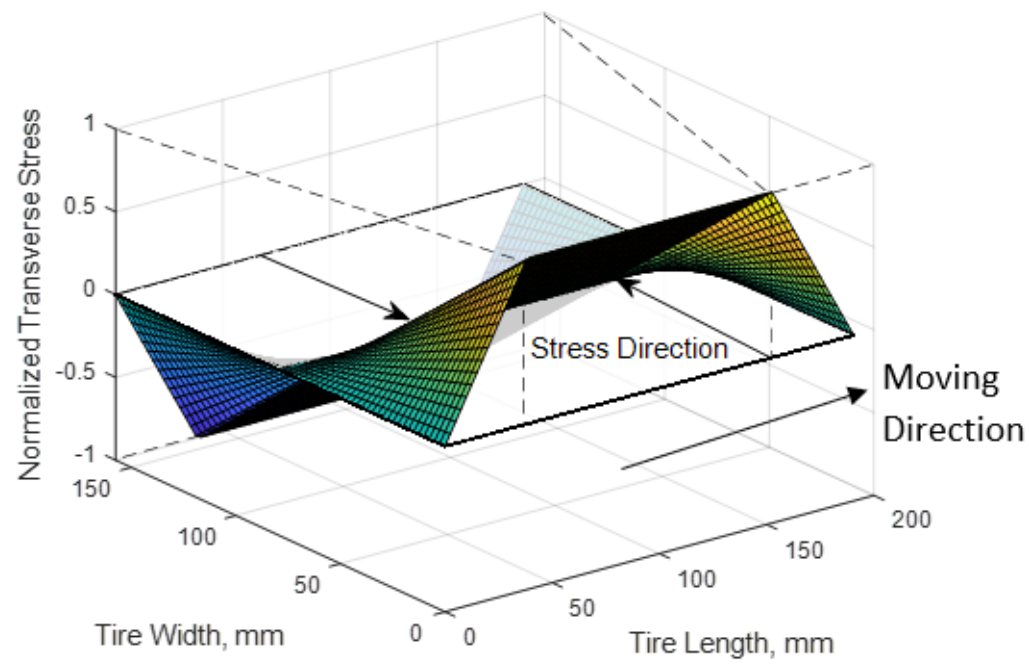

(c) Transverse Contact Stress

Figure 5. The Contact Stress between a 315/80R22.5 Tire and the Pavement

In order to simulate the contact stresses, two loading paths of $157.5-\mathrm{mm}$ (6.2-in) width and 190.5-mm (7.5-in) length are created symmetrically along the longitudinal direction with a 193.0-mm (7.6-in) space between the two wheel paths, as shown in Figure 6. Figure 7 shows the decomposed contact stresses between the tire and pavement, which are distributed nonuniformly on one wheel path in the FE model. The simulation of a moving load is achieved by creating 
successive analysis steps in which the loading areas move forward as shown in Figure 6. In each step, the load moves forward one tire path.

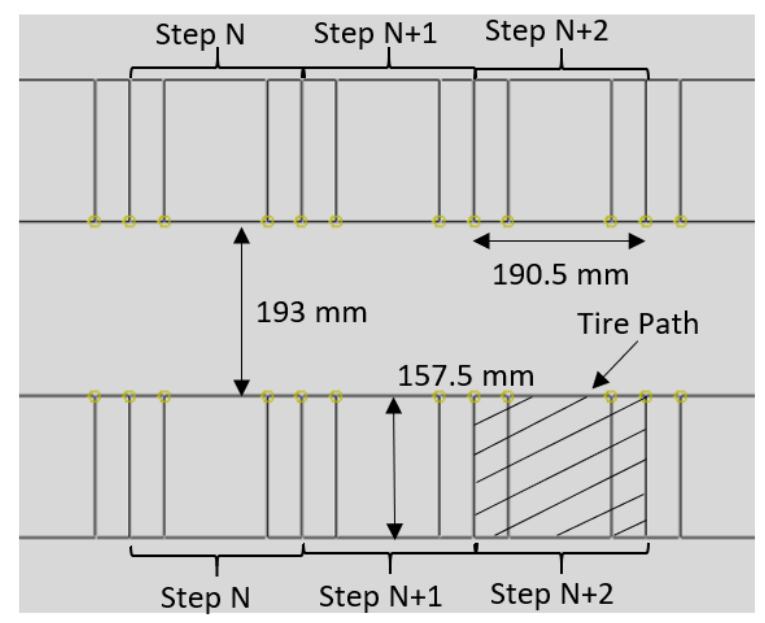

Figure 6. Simulation of Moving Loads in FE Analysis

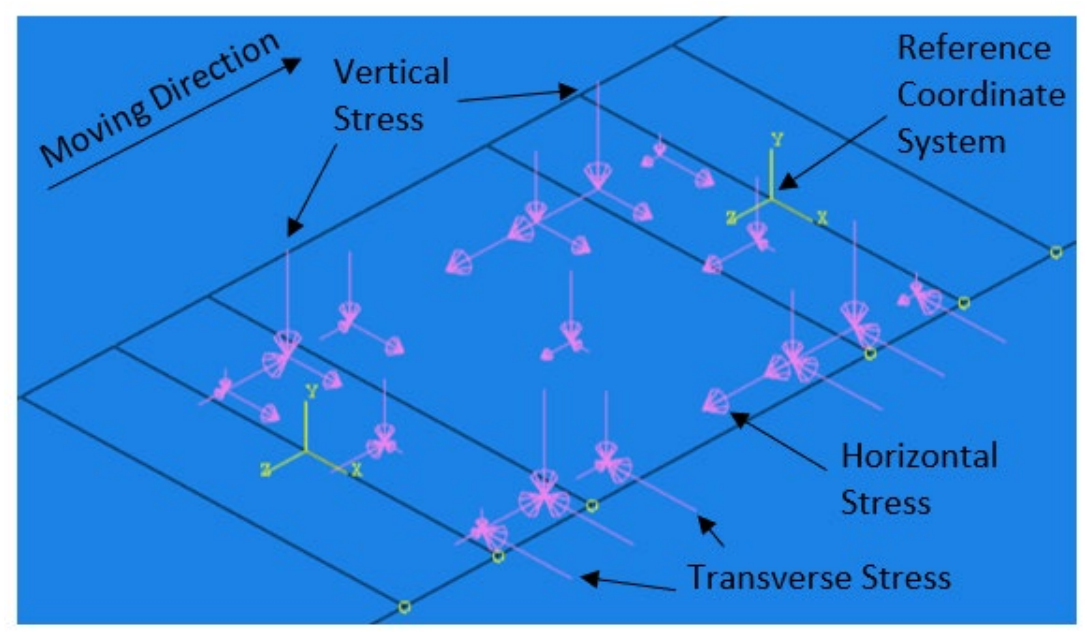

Figure 7. The Contact Stresses between Tires and the Pavement Model in the FE Analysis

The load moves along the loading paths and passes through the entire pavement model. The deflections of the entire model are collected when the load is at the center of the pavement model. The fine mesh along the loading path allows generating more data of the deflection basin for precise analysis. 


\subsection{Pavement types and material properties}

In this study, the 3D FE simulations are performed for 5 different pavement types in the field of light or heavy duty: asphalt surface over unbound base course, asphalt surface over stabilized base, concrete surface unbound base, concrete surface over stabilized base, and asphalt surface over asphalt-treated base, as listed in Table 1. For each pavement type, 4 different velocities of the moving load $(24 \mathrm{~km} / \mathrm{h}, 40 \mathrm{~km} / \mathrm{h}, 64 \mathrm{~km} / \mathrm{h}$, and $80 \mathrm{~km} / \mathrm{h})$ are selected. The material properties of each pavement type are given in Table 2. For viscoelastic surface and viscoelastic base (asphalt-treated base), the change of the material property is included to simulate the deterioration of the pavement surface with service time, as designated by I, II and III for the pavement type 5 in Table 2 .

For the selected pavement types and materials, the asphalt mixtures in the surface layer are modeled as viscoelastic materials. In addition, as the asphalt treated base course gains more applications (25), the asphalt-treated base course is applied in this study and characterized as surface materials $(26,27)$. The concrete surface and aggregate materials in the base course and subgrade are considered as elastic materials. Since the shapes of deflection basins are affected by both viscoelasticity and inertial damping (28), a typical structural inertial damping factor 5\% is selected for surface materials in both flexible and rigid pavements. For materials in the base course and subgrade which are usually in unsaturated conditions, it is found that the viscoelastic characteristics of soils measured in the laboratory experiment are more obvious as the moisture content increases (29). As the water flows through the voids in the base and subgrade with the increase of load cycles, the viscous response of the base course and subgrade materials is intensified. Hence, a typical structural inertial damping factor 5\% is also introduced in these underlying materials for energy dissipation as viscoelastic materials (30). For bound materials in the base course and subgrade, the inertial damping factor is eliminated to compare with unbound materials and evaluate the individual effect of inertial damping factor.

Table 1. Information of Pavement Type 1-5 in the 3D FE Simulation

\begin{tabular}{|c|c|c|c|c|c|c|}
\hline \multicolumn{2}{|c|}{ Pavement Type } & 1 & 2 & 3 & 4 & 5 \\
\hline $\begin{array}{c}\text { Description of } \\
\text { Pavement Structure }\end{array}$ & $\begin{array}{c}\text { Asphalt over } \\
\text { unbound base }\end{array}$ & $\begin{array}{c}\text { Asphalt over } \\
\text { stabilized } \\
\text { base }\end{array}$ & $\begin{array}{c}\text { Concrete over } \\
\text { unbound base }\end{array}$ & $\begin{array}{c}\text { Concrete over } \\
\text { stabilized } \\
\text { base }\end{array}$ & $\begin{array}{c}\text { Asphalt over } \\
\text { asphalt- } \\
\text { treated base }\end{array}$ \\
\hline Material & Surface & Viscoelastic & Viscoelastic & Elastic & Elastic & Viscoelastic \\
\hline
\end{tabular}




\begin{tabular}{|c|c|c|c|c|c|c|}
\hline & Base & $\begin{array}{c}\text { Damped } \\
\text { elastic }\end{array}$ & Elastic & $\begin{array}{c}\text { Damped } \\
\text { elastic }\end{array}$ & Elastic & $\begin{array}{c}\text { Viscoelastic } \\
\text { and damped } \\
\text { elastic }\end{array}$ \\
\hline
\end{tabular}

Table 2. Information of Material Properties and Moving Speeds in the 3D FE Simulation

\begin{tabular}{|c|c|c|c|c|c|c|c|c|c|}
\hline \multicolumn{2}{|c|}{ Pavement Type } & \multicolumn{2}{|c|}{1} & \multicolumn{2}{|c|}{2} & \multicolumn{2}{|c|}{3} & \multicolumn{2}{|c|}{4} \\
\hline \multirow{5}{*}{ Layer } & \multirow{3}{*}{ Surface } & $E_{1}, \mathrm{MPa}$ & 428 & $E_{1}, \mathrm{MPa}$ & 428 & \multirow{3}{*}{$\mathrm{E}, \mathrm{MPa}$} & \multirow{3}{*}{28000} & \multirow{3}{*}{$\mathrm{E}, \mathrm{MPa}$} & \multirow{3}{*}{28000} \\
\hline & & $\mathrm{m}$ & 0.363 & $\mathrm{~m}$ & 0.363 & & & & \\
\hline & & $\delta\left(^{\circ}\right)$ & 32.67 & $\delta\left({ }^{\circ}\right)$ & 32.67 & & & & \\
\hline & Base & $\mathrm{E}, \mathrm{MPa}$ & 517 & $\mathrm{E}, \mathrm{MPa}$ & 517 & $\mathrm{E}, \mathrm{MPa}$ & 517 & $\mathrm{E}, \mathrm{MPa}$ & 517 \\
\hline & Subgrade & $\mathrm{E}, \mathrm{MPa}$ & 31 & $\mathrm{E}, \mathrm{MPa}$ & 31 & $\mathrm{E}, \mathrm{MPa}$ & 31 & $\mathrm{E}, \mathrm{MPa}$ & 31 \\
\hline \multicolumn{2}{|c|}{ Pavement Type } & \multicolumn{8}{|c|}{5} \\
\hline \multicolumn{2}{|c|}{ Deterioration Stage } & \multicolumn{3}{|c|}{$\mathrm{I}$} & \multicolumn{3}{|c|}{ II } & \multicolumn{2}{|c|}{ III } \\
\hline \multirow{8}{*}{ Layer } & \multirow{3}{*}{ Surface } & \multicolumn{2}{|c|}{$E_{1}, \mathrm{MPa}$} & 428 & \multicolumn{2}{|c|}{$E_{1}, \mathrm{MPa}$} & 220 & $E_{1}, \mathrm{MPa}$ & 141 \\
\hline & & \multicolumn{2}{|c|}{$\mathrm{m}$} & 0.363 & \multicolumn{2}{|c|}{$\mathrm{m}$} & 0.401 & $\mathrm{~m}$ & 0.447 \\
\hline & & \multicolumn{2}{|c|}{$\delta\left({ }^{\circ}\right)$} & 32.67 & \multicolumn{2}{|c|}{$\delta\left({ }^{\circ}\right)$} & 36.09 & $\delta\left({ }^{\circ}\right)$ & 40.23 \\
\hline & \multirow{3}{*}{$\begin{array}{l}\text { Asphalt- } \\
\text { treated base }\end{array}$} & \multicolumn{2}{|c|}{$E_{1}, \mathrm{MPa}$} & 119 & \multicolumn{2}{|c|}{$E_{1}, \mathrm{MPa}$} & 70 & $E_{1}, \mathrm{MPa}$ & 17 \\
\hline & & \multicolumn{2}{|c|}{$\mathrm{m}$} & 0.202 & \multicolumn{2}{|c|}{$\mathrm{m}$} & 0.259 & $\mathrm{~m}$ & 0.351 \\
\hline & & \multicolumn{2}{|c|}{$\delta\left({ }^{\circ}\right)$} & 18.18 & \multicolumn{2}{|c|}{$\delta\left({ }^{\circ}\right)$} & 23.31 & $\delta\left({ }^{\circ}\right)$ & 31.59 \\
\hline & $\begin{array}{l}\text { Unbound } \\
\text { base }\end{array}$ & \multicolumn{2}{|c|}{ E, MPa } & 517 & \multicolumn{2}{|c|}{$\mathrm{E}, \mathrm{MPa}$} & 517 & $\mathrm{E}, \mathrm{MPa}$ & 517 \\
\hline & Subgrade & $\mathrm{E}, \mathrm{N}$ & & 31 & & $\mathrm{MPa}$ & 31 & $\mathrm{E}, \mathrm{MPa}$ & 31 \\
\hline \multicolumn{2}{|c|}{ Moving Speed } & \\
\hline
\end{tabular}

Several models are available to describe viscoelastic properties. In this study, a fractional power of time is applied in the relaxation function to describe the stress relaxation as in Equation 4.

$$
E(t)=E_{1} t^{-m}
$$

where $E(t)=$ relaxation modulus; and $E_{1}, m=$ material coefficients.

An approximate relationship (3) between the power-law function coefficient $\mathrm{m}$ and the phase angle $\delta$ (radius) is developed for viscoelastic materials as in Equation 5.

$$
\delta=\frac{\pi}{2} m
$$

The phenomenon of relaxation can also be explained by a Prony series - sum of decaying exponentials (31). The relaxation modulus in the form of Prony series can be expressed in Equation 6:

$$
E(t)=E_{\infty}+\sum_{i=1}^{N} E_{i} e^{-t / \tau_{i}}
$$

in which 


$$
\begin{gathered}
E_{\infty}=E_{0}-\sum_{i=1}^{N} E_{i} \\
E_{i}=e_{i} E_{0}
\end{gathered}
$$

where $E(t)=$ relaxation modulus; $E_{\infty}=$ long-term relaxation modulus; $E_{i}=$ components of relaxation modulus; $E_{0}=$ instantaneous modulus; and $e_{i}, \tau_{i}=$ material coefficients.

A Prony series expansion is one of the expressions used in the ABAQUS to define viscoelastic properties of materials, as follows in Equation 9 and Equation 10 (32),

$$
\begin{gathered}
\left.g_{R}(t)=1-\sum_{i=1}^{N} \bar{g}_{i}^{p}\left(1-e^{-t / \tau_{i}^{G}}\right)\right] \\
g_{R}(t)=G_{R}(t) / G_{0}
\end{gathered}
$$

where $G_{R}(t)=$ shear relaxation modulus; $G_{0}=$ instantaneous shear modulus; $\bar{g}_{i}^{p}, \tau_{i}^{G}=$ material coefficients.

The process to input the viscoelastic properties of the pavement surface and asphalttreated base course materials into the ABAQUS is as follows:

1) Represent the relaxation modulus by Equation 4 and determine the values of $E_{1}$ and $m$;

2) Adjust the coefficients of the Prony series in Equation 6 to fit the relaxation modulus in Equation 4;

3) Convert the relaxation modulus in Equation 6 to the shear relaxation modulus in Equation 9 , and determine all of the coefficients, which are input into the ABAQUS.

\section{Results and Discussions}

The deflection basin of the pavement from the ABAQUS is composed of deflection data at discrete points, of which the number is controlled by the mesh size. Consequently, in order to accurately capture the maximum absolute value of the deflection basin, an appropriate continuous curve is needed to fit these discrete defection points. Therefore, a Fourier series function is applied to fit the discrete deflection data, which is expressed in Equation 11,

$$
d(x)=a_{0}+\sum_{i=1}^{N} a_{i} \cos (\omega x)+b_{i} \sin (\omega x)
$$


where $d=$ vertical deflection; $x=$ distance from the loading center; $a_{0}, a_{i}, b_{i}, \omega=$ fitting parameters. Then the fitting curve of the deflection basin is used to determine the length of the basin and lag distance.

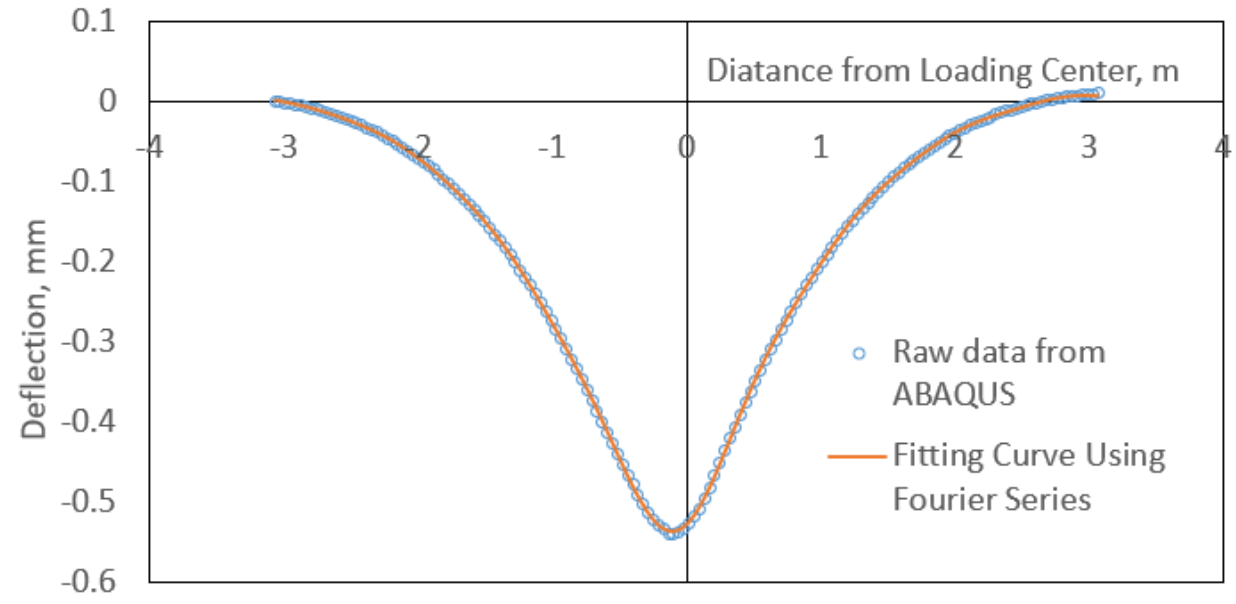

\section{Figure 8. Example of Comparison of Deflection Basins Using Data from ABAQUS and Fourier Series Function}

Figure 8 shows the comparison of the fitted deflection basin and deflection data from the ABAQUS in one case. It is clear that the Fourier series function matches well with the deflection basin. For the rest of the cases in this study, the Fourier series function works well and the values of $R^{2}$ between the data obtained from the ABAQUS and that predicted by the fitting curve are all above 0.99 .

\subsection{Deflection basins of different types of pavements}

To illustrate the effects of material properties on pavement responses under moving loads, the moving loads of the same speed are executed on pavement Types 1-4, of which Type 1-2 represent flexible pavements and Type 3-4 represent rigid pavements. The results are given in Table 3 and Figure 9. In both types of pavements, the asymmetry of the deflection basins is reflected with a steep leading edge and a shallow trailing edge. There are lag distances between the locations of the maximum deflection and the center of the loading which are shown clearly in flexible pavements. In addition, the lag distance increases and the magnitude of the deflection basin decreases as the damping factor of the base course is considered. It indicates that the asymmetry of the deflection basin is caused by both material viscoelasticity and damping factor, 
which in turn points out the significance of considering these two factors in the analysis of pavement systems.

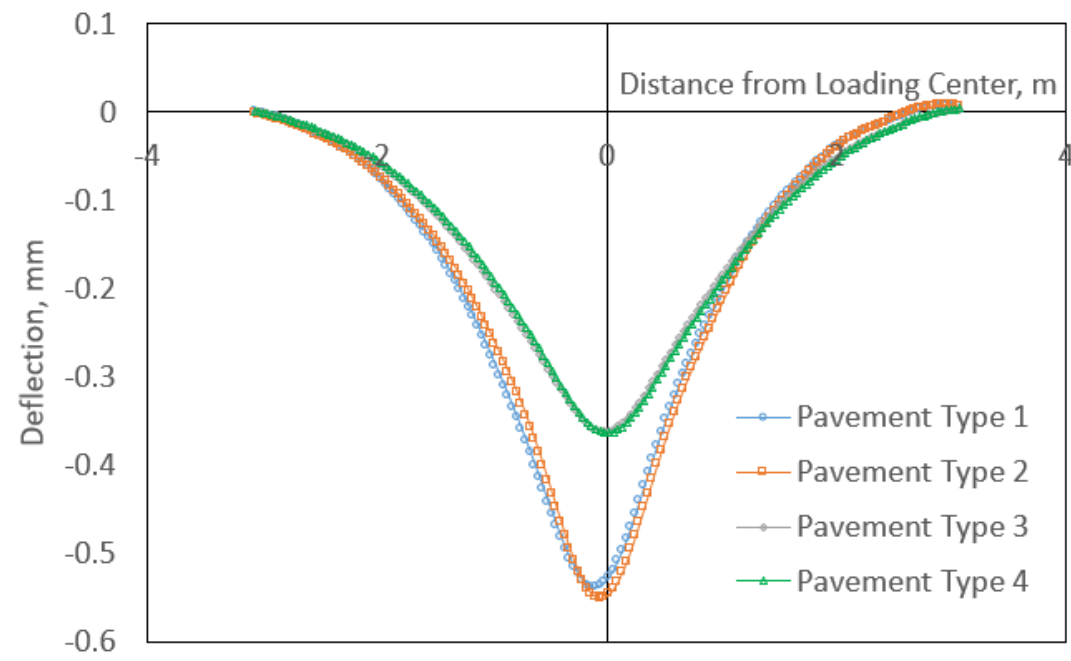

(a) Moving Load v=80 km/h

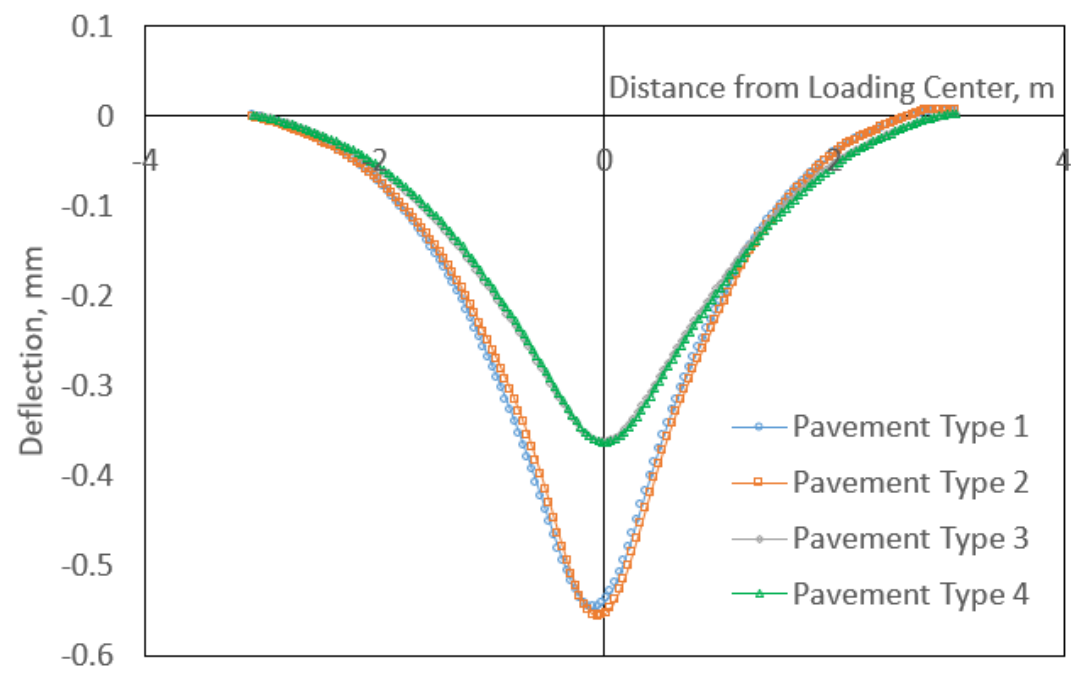

(b) Moving Load v=64 km/h

Figure 9. Deflection Basins of Pavement Type 1-4 under Moving Loads 
Table 3. Lag Distance and Lag Angle of Pavement Type 1-4 under Moving Loads

\begin{tabular}{|c|c|c|c|c|c|}
\hline \multirow{2}{*}{ Moving Speed, km/h } & Pavement Type & 1 & 2 & 3 & 4 \\
\hline \multirow{2}{*}{80} & Lag Distance, cm & 10.54 & 5.49 & 2.09 & 0 \\
\cline { 2 - 6 } & Lag Angle, degree & 6.66 & 3.45 & 1.28 & 0 \\
\hline \multirow{2}{*}{64} & Lag Distance, cm & 9.06 & 4.86 & 1.29 & 0 \\
\cline { 2 - 6 } & Lag Angle, degree & 5.7 & 3.04 & 0.79 & 0 \\
\hline
\end{tabular}

\subsection{Effects of moving load speeds}

Since the viscoelasticity of materials and damping factor are considered in this study, the timedependent properties such as modulus should be reflected in the pavement responses under different lengths of loading duration. Figure 10 shows deflection basins of the pavement model under different moving loads. As illustrated in Figure 10, the asymmetry of the deflection basins can be seen clearly from the steep leading edge and shallow trailing edge. The lag distance between the maximum deflection and loading center exists in most deflection basins. Especially, when comparing the magnified bottom part of each deflection basin, an obvious trend shows that with the increase of the moving speed, the maximum deflection decreases and the lag distance increases, which is also seen from results in Table 4. Figure 10 and Table 4 demonstrate the sensitivity of the deflection basin to the speed of the moving load.

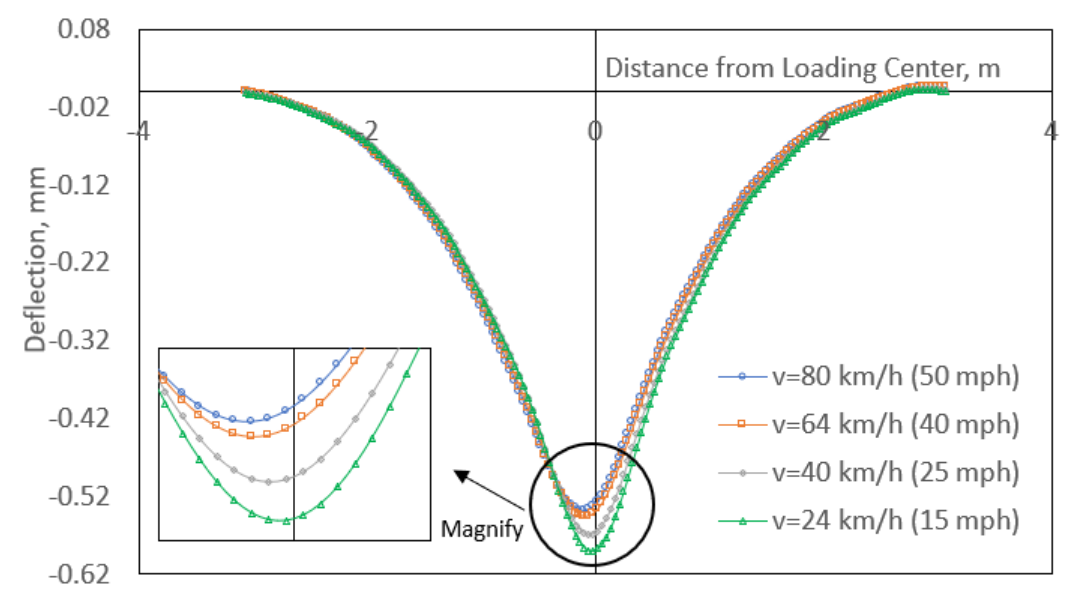

(a) Pavement Type 1 


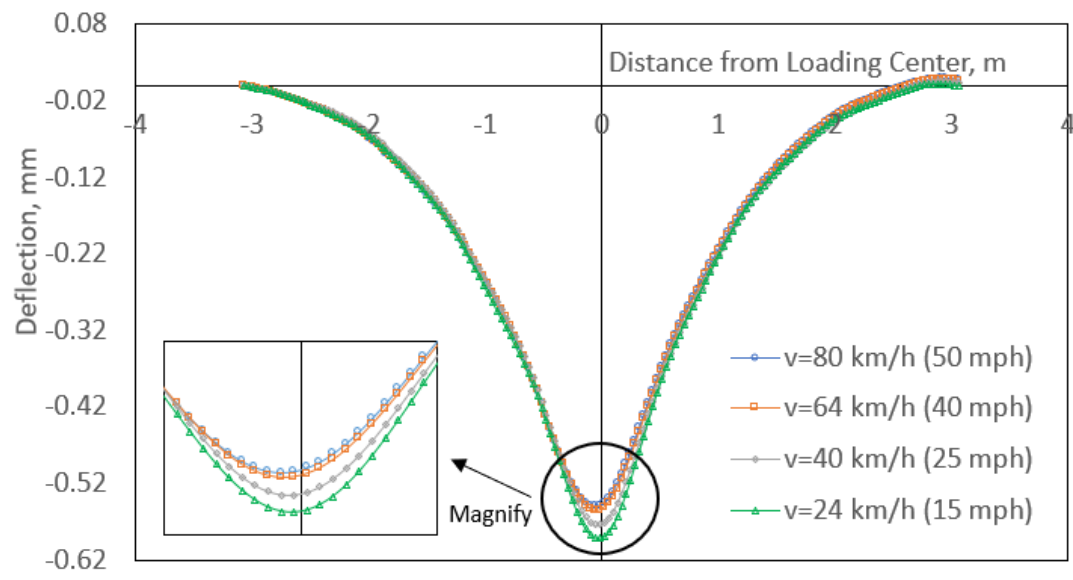

(b) Pavement Type 2

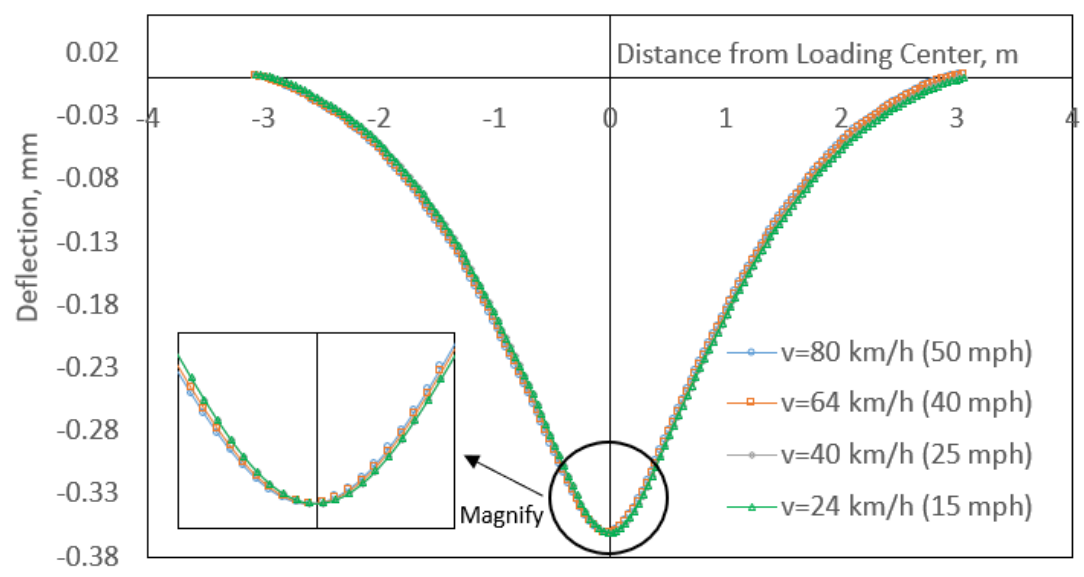

(c) Pavement Type 3

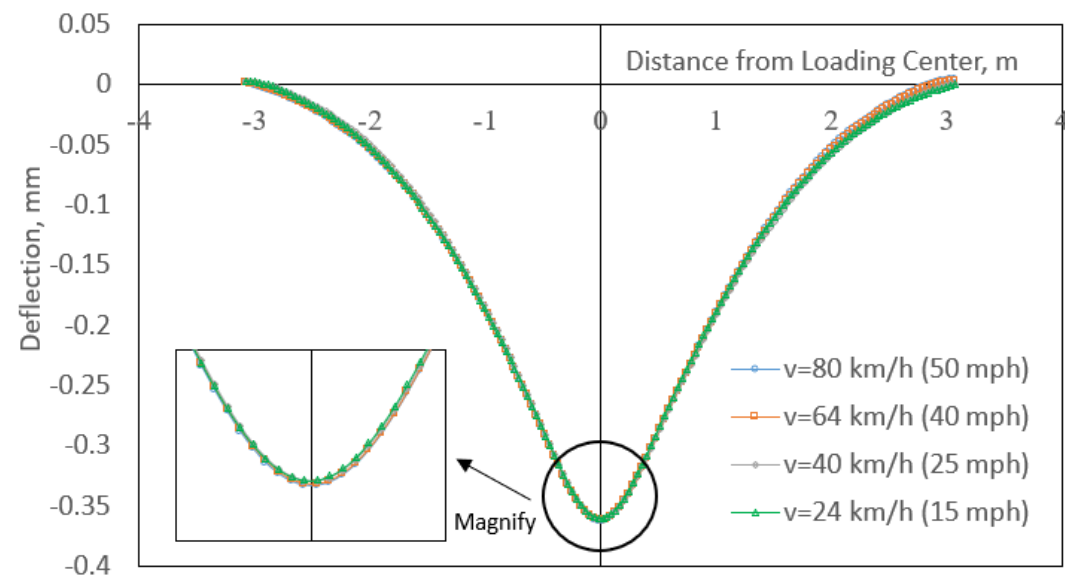

(d) Pavement Type 4 


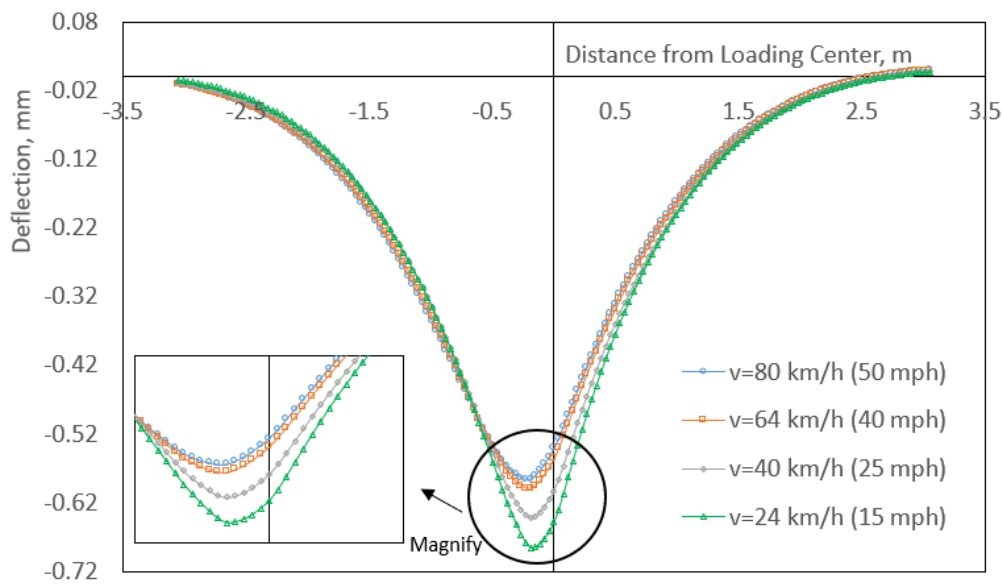

(e) Pavement Type 5 at Deterioration Stage I

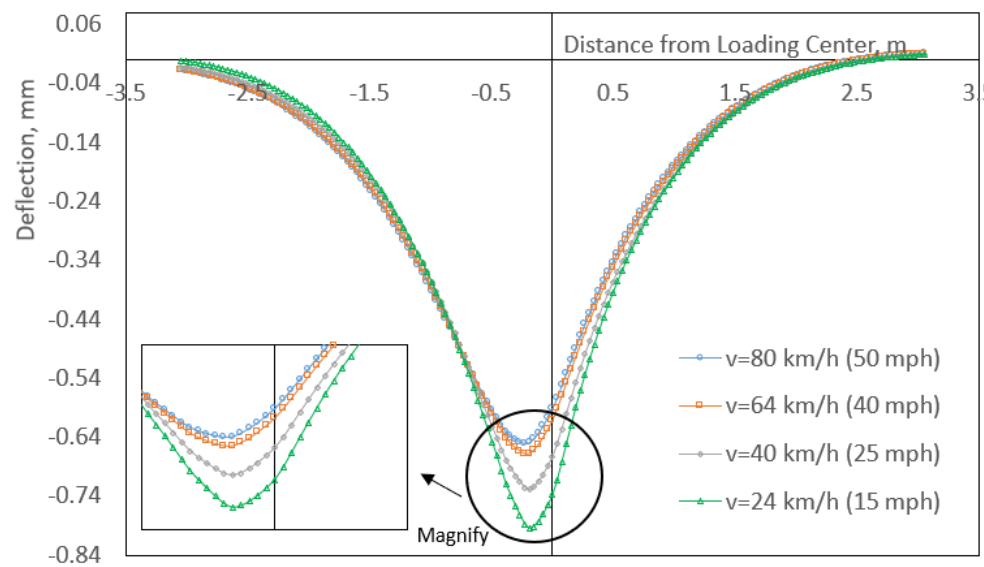

(f) Pavement Type 5 at Deterioration Stage II

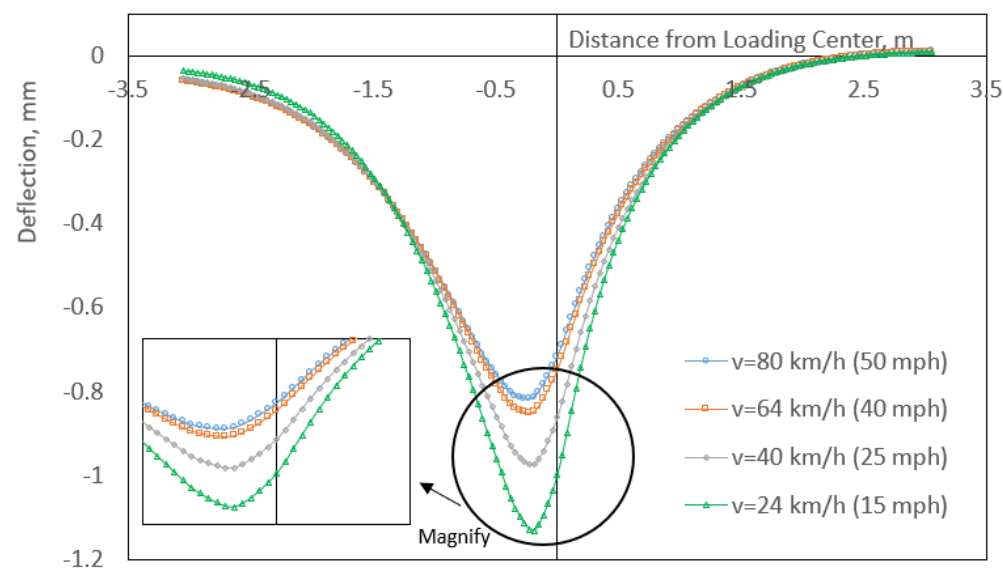

(g) Pavement Type 5 at Deterioration Stage III

Figure 10. Deflection Basins of Pavement Type 1-5 under Four Moving Loads 
Table 4. Lag Distance and Lag Angle of Pavement Type 1-5 under Four Moving Loads

\begin{tabular}{|c|c|c|c|c|c|c|c|c|c|c|c|c|c|c|c|}
\hline \multirow{2}{*}{\multicolumn{2}{|c|}{$\begin{array}{l}\text { Deflection } \\
\text { Basin } \\
\text { Parameter } \\
\text { Pavement } \\
\text { Type } \\
\end{array}$}} & \multicolumn{7}{|c|}{ Lag Distance, $\mathrm{cm}$} & \multicolumn{7}{|c|}{ Lag Angle, degree } \\
\hline & & 1 & 2 & 3 & 4 & & 5 & & 1 & 2 & 3 & 4 & & 5 & \\
\hline \multicolumn{2}{|c|}{$\begin{array}{l}\text { Deterioration } \\
\text { Stage }\end{array}$} & \multicolumn{4}{|c|}{ N/A } & I & II & III & \multicolumn{4}{|c|}{$\mathrm{N} / \mathrm{A}$} & I & II & III \\
\hline \multirow{4}{*}{$\begin{array}{l}\text { Speed } \\
\text { of } \\
\mathrm{Load}, \\
\mathrm{km} / \mathrm{h}\end{array}$} & 80 & 10.5 & 5.5 & 2.1 & 0 & 23.3 & 24.2 & 28.1 & 6.7 & 3.5 & 1.3 & 0 & 14.9 & 15.4 & 17.8 \\
\hline & 64 & 9.1 & 4.9 & 1.3 & 0 & 21.9 & 22.9 & 26.6 & 5.7 & 3.0 & 0.8 & 0 & 14.1 & 14.6 & 16.9 \\
\hline & 40 & 5.4 & 3.4 & 0.1 & 0 & 18.3 & 19.6 & 23.6 & 3.1 & 2.1 & 0.04 & 0 & 12.0 & 12.8 & 15.5 \\
\hline & 24 & 3.4 & 2.7 & 0.1 & 0 & 16.2 & 17.5 & 21.9 & 1.9 & 1.6 & 0.07 & 0 & 10.5 & 11.5 & 14.0 \\
\hline
\end{tabular}

\subsection{Effects of pavement deterioration conditions}

To study the effects of deterioration condition of a pavement on deflection basins under moving loads, the deflection basins of the pavement model at three typical stages of its service life under the same moving load are illustrated in Figure 11. The variation of a pavement's fatigue cracking deterioration conditions is reflected in the values of the modulus and the phase angle as presented in Figure 2 and Table 2. With the increase of load cycles, the modulus of pavement materials decreases while the phase angle increases. Similar to Figure 9, the two main points (steep leading edge and shallow trailing edge; the lag distance between the maximum deflection and the loading center) are observed in each complete deflection basin. From the magnified lower parts in Figure 11, it can be concluded that the maximum deflection increases when the increasing number of load cycles causes damage to the pavement, which agrees with the common understanding. Furthermore, the change of the lag distance is obvious from Stage 1 to Stage 3. This is because the viscous response of pavement materials is enhanced, which is attributed to the growing cracks and voids in the pavement surface layer, and moisture accumulation and plastic deformation in the base course layer. Such changes will have effects on material properties of the layers and eventually be reflected in the deflection basins. 


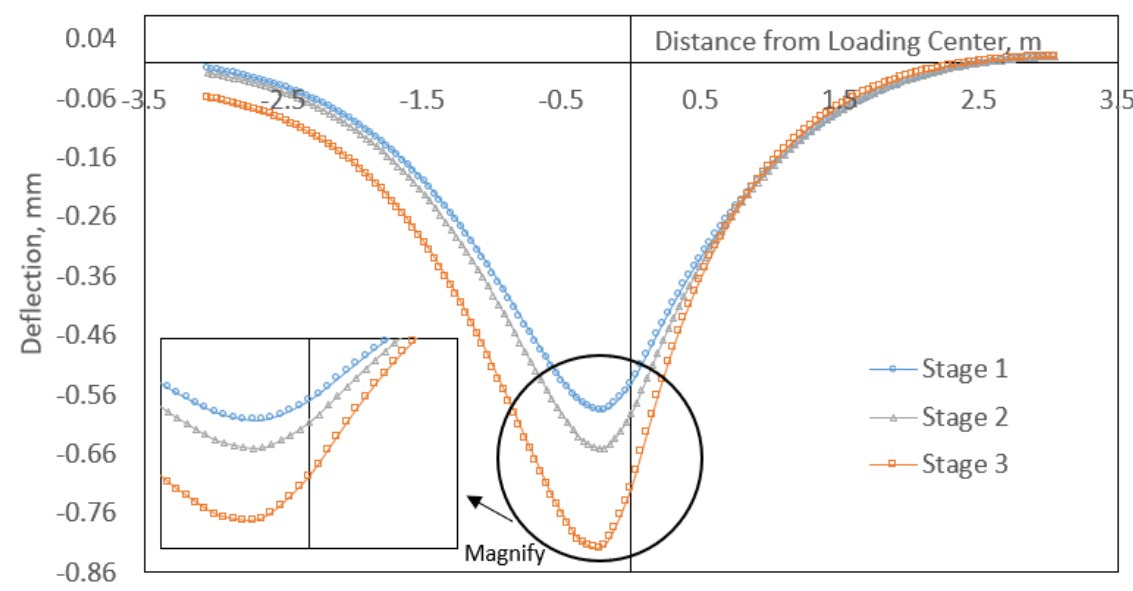

(a) Moving Load v=80 km/h

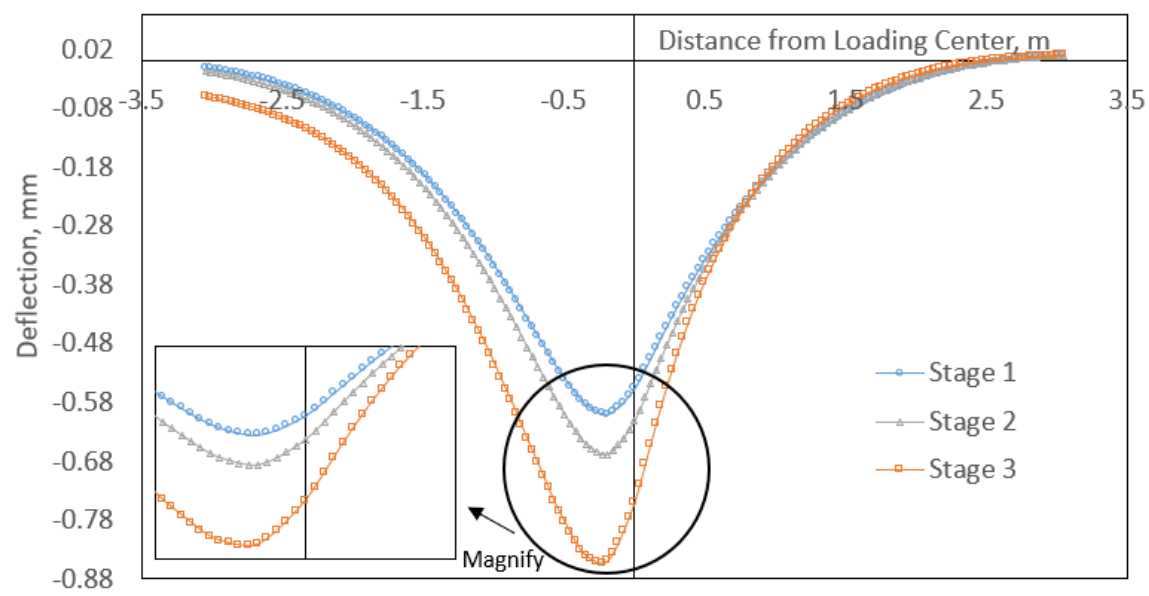

(b) Moving Load v=64 km/h

Figure 11. Deflection Basins of Pavement at Different Deterioration Stages under Moving Loads

Figures 10(e), 10(f), 10(g) and 11 show that the deflection basins of the pavement model in different deterioration conditions and under different moving speeds. The results illustrate that the deterioration condition of the pavements affects the deflection basin in terms of its asymmetry and maximum deflection, which are also sensitive to the speed of the moving load. Therefore, it is natural to consider the possibility of visualizing the deterioration condition of a pavement directly from its deflection basin under a moving load. The lag angle defined in Equation 2 represents the characteristics of both the deflection basins (length and lag distance) and moving loads (speed). The relationship between the pavement lag angle and the material phase angle is studied herein. Figure 12 shows the correlations between the lag angles calculated 
from the deflection basins and phase angles of both the surface layer and asphalt-treated base course. The results provide evidence for a potential relationship between the newly defined lag angle and the viscoelastic properties of pavement materials.

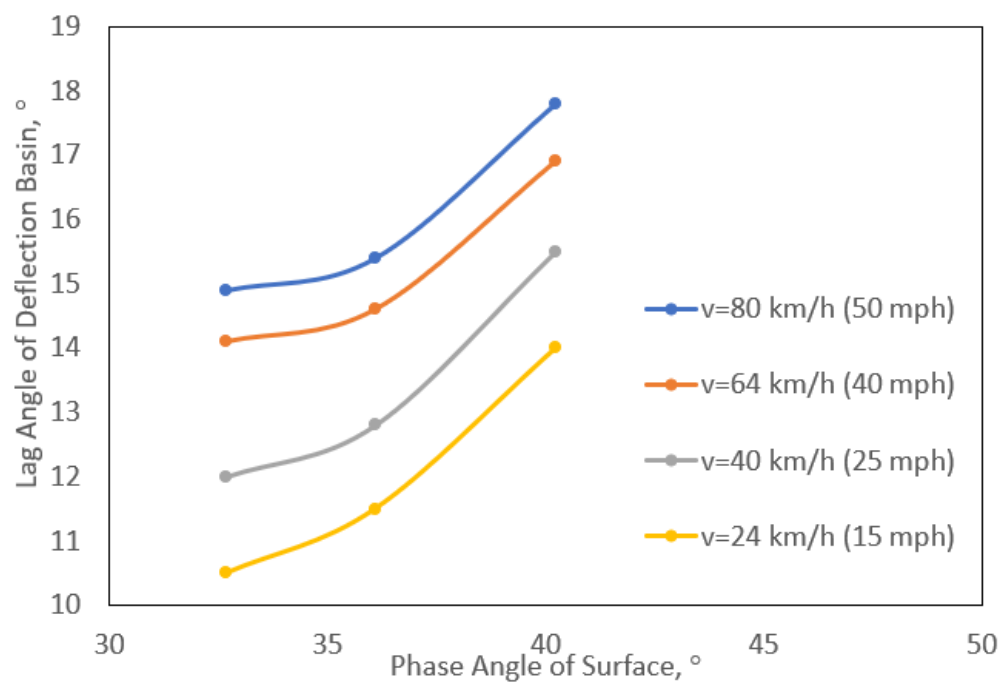

(a) Surface Layer

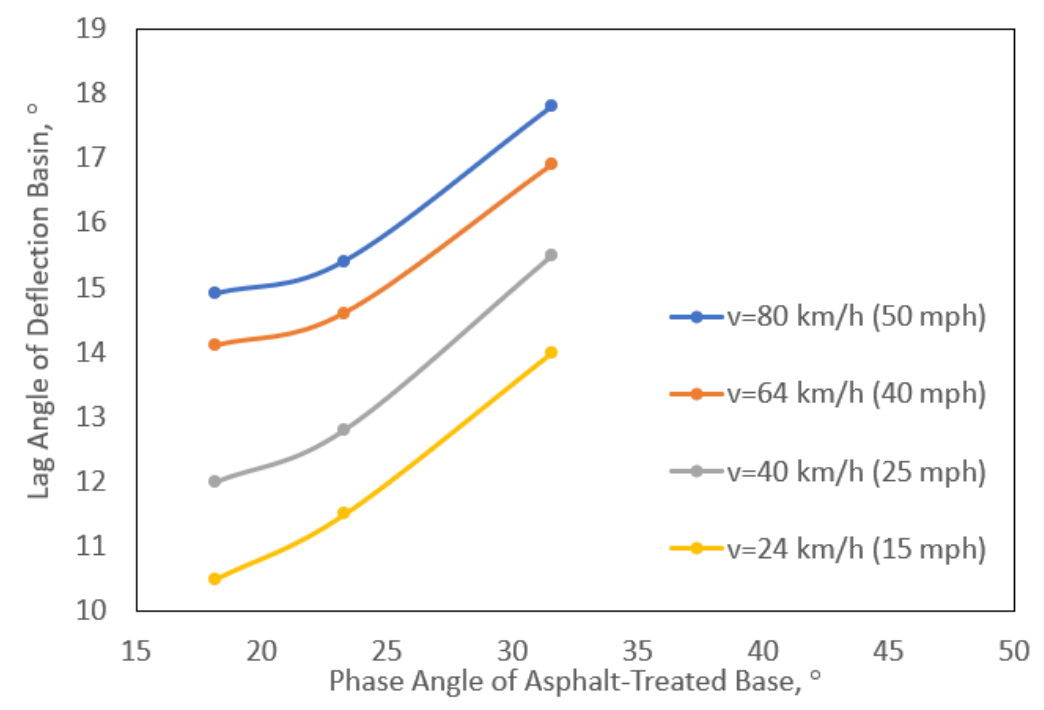

(b) Base Course

Figure 12. Relationship between Lag Angle and Phase Angle of Pavement Materials

\subsection{Comparisons with field measurements}

The purpose of this section is to compare the predicted deflection basin by the 3D FE model proposed above with those simulated and/or measured by other researchers. Recently, a project 
was conducted to simulate pavements under moving loads and compare numerical results with data measured from field tests with Traffic Speed Deflection Devices RWD and TSD to measure the deflection and the deflection velocity of pavements respectively $(33,34)$. As the RWD measures the deflection of a pavement, the TSD applies the Doppler technique to measure the vertical deflection velocity. The slope of the deflection basin is the ratio of the deflection velocity to the moving velocity (35). Based on the simulation results and field measurements from this project, a comparative study is performed. A new 3D pavement model is constructed following the method presented in the third section above. The pavement model has the same structure and material properties $(33,34)$ as those in the project using the RWD and TSD. The viscoelastic material properties of the surface layer were measured from the laboratory tests; the elastic properties of the base and subgrade are obtained from the FWD measurements. Furthermore, the material properties such as the inertial damping and density which are not available in the literature are considered in the 3D pavement model and taken typical values.

Figure 13 shows the results of the comparison. The FE data are provided by the 3D pavement model considering material viscoelasticity and structural inertial damping. The asymmetry of the deflection basin can be seen clearly and the lag distance occurs between locations of the loading center and the maximum deflection from Figure 13. The two discrete data points in Figure 13(a) are measured by the RWD, and six discrete data points of the deflection slope in Figure 13(b) are measured by the TSD. Considering the variability in the field measurements by the RWD and TSD, the match between the FE simulation results and field data is good.

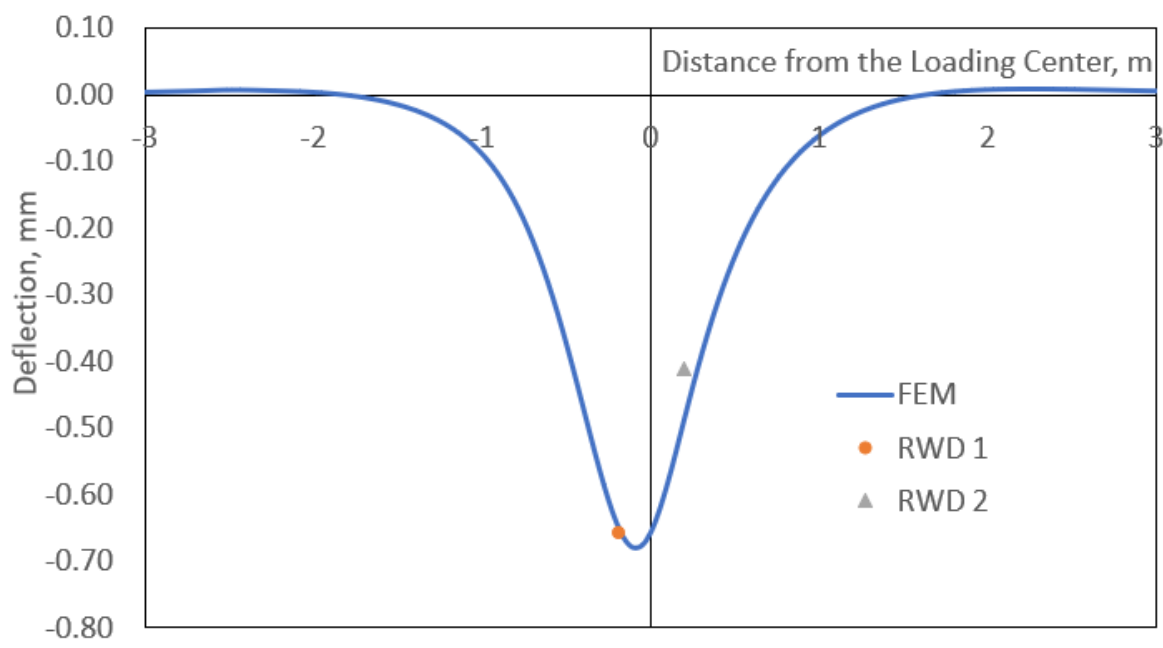

(a) RWD Data 


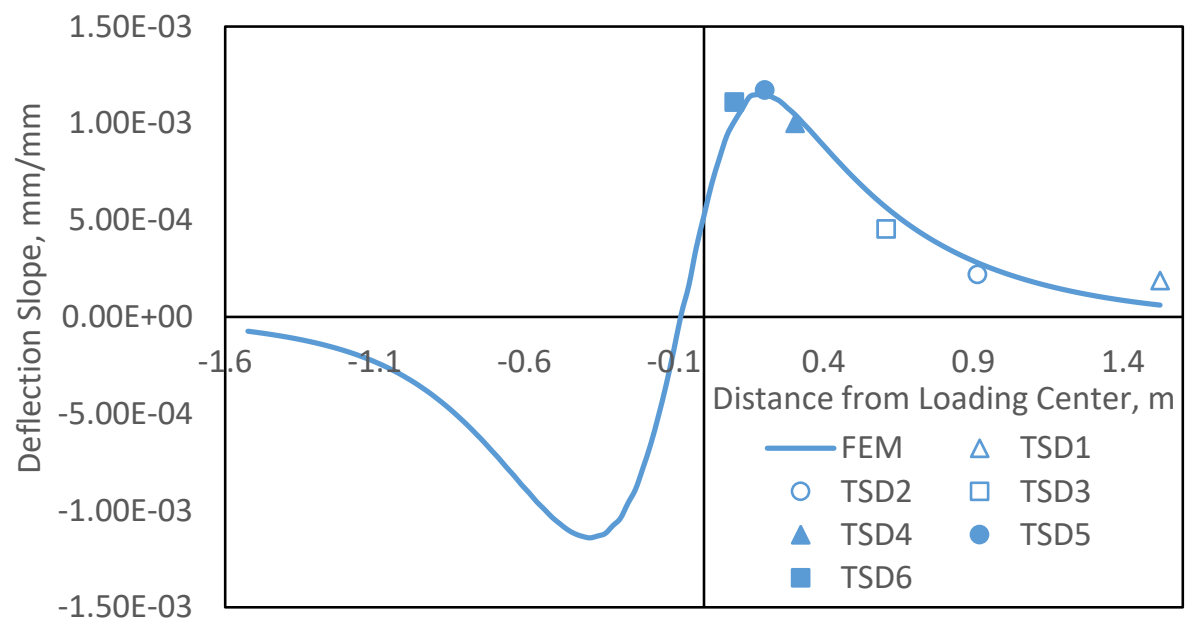

(b) TSD Data

Figure 13. Comparison of the 3D FE Model Results and Field Data

\section{Conclusions and Future Work}

This paper presents the results of simulating the deflection basins of pavements under moving loads using the finite element analysis. The 3D FE pavement model is constructed and analyzed with different material properties and moving speeds. The major contributions of this paper are summarized as follows:

- The 3D FE analysis reveals that the deflection basin of a pavement exhibits an asymmetric shape under a moving load. It has a steep leading edge and a shallow trailing edge along the direction of the moving load.

- The 3D FE results shows that there is a time lag between the maximum deflection and the center of the load for flexible pavements and some rigid pavements. This time lag is utilized to define a new term of "lag angle".

- The viscoelasticity of the pavement materials and structural inertial damping of the pavement structure affect the shape and lag angle of the deflection basin. Both of them need to be considered in order to accurately capture the features of the deflection basin under moving loads. 
- The speeds of the moving loads influence the shape and lag angle of the deflection basin of pavements. A higher speed results in a higher lag distance between the maximum deflection and the loading center in flexible pavements and some rigid pavements.

- The pavement deterioration conditions affect the shape and lag angle of the deflection basin. As the severity of pavement distresses increases, the time lag of the deflection basin increases. This is attributed to the increasing loss of viscos dissipated energy due to the growing microcracks in the pavement surface layer and the accumulation of moisture and plastic deformation in the base course layer.

- It is found that the lag angle of the deflection basin is closely related to the phase angle of the viscoelastic pavement materials.

- The deflection basin predicted by the 3D FE analysis is compared to the field measurements made with the RWD and TSD. The simulation has the same pavement structure and laboratory-measured material properties as the real pavement tested by the RWD and TSD. Based on the limited RWD and TSD data, the simulation results are comparable to the field deflections obtained at high speed.

It is worth mentioning that the conclusions above are based on the limited simulation for 28 cases ( 7 cases $x 4$ moving speeds) performed in this study. This is mainly due to the 3D FE analysis proposed above consumes considerable time and computational efforts. In the future, the efficiency of the FE analysis is planned to be enhanced so as to conduct a comprehensive parametric and sensitivity analysis for deflection basins of pavements under high-speed moving loads. 


\section{Acknowledgements}

The authors gratefully acknowledge the support provided by the Texas Department of

Transportation (TxDOT) under Project 0-6869: Advancing Innovative High-Speed Remote-

Sensing Highway Infrastructure Assessment Using Emerging Technologies. 


\section{References:}

[1]. J. A. Bay, I. I. Stokoe, H. Kenneth, Development of a rolling dynamic deflectometer for continuous deflection testing of pavements. Report No. FHWA/TX-99/1422-3F, (1998), University of Texas at Austin, Center for Transportation Research.

[2]. AASHTO, AASHTO Guide for Design of Pavement Structures, American Association of State Highway and Transportation Officials, Washington D.C., 1993.

[3]. R. L. Lytton, Backcalculation of pavement layer properties. In Nondestructive testing of pavements and backcalculation of moduli. (1989), ASTM International.

[4]. D. A. Steele, W. R. Vavrik, Rolling wheel deflectometer (RWD) demonstration and comparison to other devices in Texas. ARA Project 15874, (2004), Federal Highway Administration, Washington D.C.

[5]. S. Nasimifar, 3D-move simulation of TSDDs for pavement characterizations, Thesis (PhD), (2015), University of Nevada, Reno.

[6]. L. Sun, X. Deng, Predicting vertical dynamic loads caused by vehicle-pavement interaction. Journal of transportation engineering, (1998), 124(5), 470-478.

[7]. I. L. Howard, K. A. Warren, Finite-element modeling of instrumented flexible pavements under stationary transient loading. Journal of Transportation Engineering, (2009), 135(2), 53-61.

[8]. S. M. Zaghloul, T. White, Use of a three-dimensional, dynamic finite element program for analysis of flexible pavement. Transportation research record, (1993), 1388.

[9]. W. Uddin, D. Zhang, F. Fernandez, Finite element simulation of pavement discontinuities and dynamic load response. Transportation Research Record, (1994), 1448.

[10]. R. M. Mulungye, P. M. O. Owende, K. Mellon, Analysis of response of flexible pavements using finite element method. The ITB Journal, (2005), 6(2), 5.

[11]. M. Li, H. Wang, G. Xu, P. Xie, Finite element modeling and parametric analysis of viscoelastic and nonlinear pavement responses under dynamic FWD loading. Construction and Building Materials, (2017), 141, 23-35.

[12]. M. De Beer, C. Fisher, F. J. Jooste, Evaluation of non-uniform tyre contact stresses on thin asphalt pavements. In Ninth international conference on asphalt pavements, (2002), $5,19-22$.

[13]. I. L. Al-Qadi, H. Wang, Pavement damage due to different tire and loading configurations on secondary roads. NEXTRANS Project No. 008IY01, (2009), NEXTRANS, West Lafayette.

[14]. I. L. Al-Qadi, M. A. Elseifi, P. J. Yoo, Characterization of pavement damage due to different tire configurations. Journal of the Association of Asphalt Paving Technologists, (2005), 74, 921-962.

[15]. S. Li, Z. Guo, Y. Yang, Dynamic viscoelastic response of an instrumented asphalt pavement under various axles with non-uniform stress distribution. Road Materials and Pavement Design, (2016), 17(2), 446-465. 
[16]. T. D. Gillespie, Fundamentals of vehicle dynamics. (1992), Society of Automotive Engineers (SAE).

[17]. Y. H. Huang, Pavement analysis and design. (2004), Pearson/Prentice Hall, Upper Saddle River, NJ.

[18]. M. S. A. Hardy, D. Cebon, Importance of speed and frequency in flexible pavement response. Journal of Engineering Mechanics, (1994), 120(3), 463-482.

[19]. L. Khazanovich, A. Booshehrian, Dynamic viscoelastic analysis of falling weight deflectometer deflections for rigid and flexible pavements. Transportation Research Record: Journal of the Transportation Research Board, (2015), 2525, 31-39.

[20]. R. S. Lakes, Viscoelastic materials. (2009), Cambridge University Press, New York.

[21]. H. Di Benedetto, A. Asayer Soltani, P. Chaverot, The fatigue of the bituminous mixes: a pertinent approach of its measurement and its characterization. In Eurashpalt \& Eurobitume Congress, (1996), Vol. 2, Strasbourg, France.

[22]. R. Reese, Properties of aged asphalt binder related to asphalt concrete fatigue life. Journal of the Association of Asphalt Paving Technologists, (1997), 66.

[23]. G. M. Rowe, M. G. Bouldin, Improved techniques to evaluate the fatigue resistance of asphaltic mixtures. In 2nd Eurasphalt \& Eurobitume Congress Barcelona, (2000), Vol. 2000.

[24]. M. Ling, X. Luo, S. Hu, F. Gu, R. L. Lytton, Numerical modeling and artificial neural network for predicting J-integral of top-down cracking in asphalt pavement. Transportation Research Record: Journal of the Transportation Research Board, (2017), 2631, 83-95.

[25]. L. N. Mohammad, M. D. Nazzal, B. King, A. Austin, Development of a design methodology for asphalt treated mixtures, Report No. FHWA/LA. 09/453. (2013), Louisiana Transportation Research Center.

[26]. P. J. Yoo, I. L. Al-Qadi, The truth and myth of fatigue cracking potential in hot-mix asphalt: numerical analysis and validation. Asphalt Paving TechnologyProceedings, (2008), 77, 549.

[27]. F. Gu, W. Ma, R. C. West, A. J. Taylor, Y. Zhang, Structural performance and sustainability assessment of cold central-plant and in-place recycled asphalt pavements: A case study. Journal of Cleaner Production, 208, (2019), 1513-1523.

[28]. Y. Deng, Three-dimensional numerical simulation of pavements deflection basins under moving loads, Thesis (Master), (2017), Texas A\&M University, College Station.

[29]. R. L. Kondner, M. M. Ho, Viscoelastic response of a cohesive soil in the frequency domain. Transactions of the Society of Rheology, (1965), 9(2), 329-342.

[30]. I. L. Al-Qadi, H. Wang, P. J. Yoo, S. H. Dessouky, Dynamic analysis and in situ validation of perpetual pavement response to vehicular loading. Transportation research record, (2008), 2087(1), 29-39.

[31]. M. A. Biot, Theory of stress-strain relations in anisotropic viscoelasticity and relaxation phenomena. Journal of Applied Physics, (1954), 25(11), 1385-1391. 
[32]. Abaqus 6.12, Documentation and User Manual. (2012), Dassault Systèmes Simulia Corp.

[33]. M. Nasimifar, R. V. Siddharthan, G. R.Rada, S. Nazarian, Dynamic analyses of traffic speed deflection devices. International Journal of Pavement Engineering, (2017), 18(5), 381-390.

[34]. G. R. Rada, S. Nazarian, B. A. Visintine, R. Siddharthan, S. Thyagarajan, Pavement structural evaluation at the network level, Report No. FHWA-HRT-15-074, (2016), Amec Foster Wheeler Environment \& Infrastructure, INC., The University of Texas at El Paso, University of Nevada Reno.

[35]. S. Rasmussen, L. Aagaard, S. Baltzer, J. Krarup, A comparison of two years of network level measurements with the Traffic Speed Deflectometer, In 2nd European Transport Research Arena, (2008), Ljubljana. 